\title{
Karakuri Ningyo Dolls and Toyota Commemorative Museum as Resources of Industrial Tourism
}

\author{
Masami Morita ${ }^{a}$, Shinji Moritab
}

\begin{abstract}
There are many Karakuri Ningyo dolls in the Chubu district of Japan. Karakuri Ningyo dolls are, so to speak, wooden automata with exemplification of creative technology unique to Japan. But Karakuri Ningyo dolls have not been appreciated as a significant resource of industrial tourism. The Chubu district of Japan has conserved and cultivated its treasures of Karakuri Ningyo dolls and Karakuri culture in the Toyota Commemorative Museum of Industry and Technology and Toyota company culture. The Museum provides an opportunity to consider the areal power to build up inter-connectivity between several local industrial elements; cotton manufacture as endogenous industry, nearby wood production and the assembly of skilled craftsman of wood working. So the region is one of the representative industrial tourism destinations which the tourist gaze directs upon. However, the region has not been generally recognized as an attractive destination for industrial tourism. This paper explored the significance of Chubu's resources of industrial tourism by tracing the technological development of Karakuri Ningyo dolls and Toyoda looms. This paper also demonstrated the historical uniqueness of the process of the modernaization of Japan.
\end{abstract}

\section{Keywords}

Karakuri Ningyo dolls, Karakuri culture, Toyoda looms, Toyota company culture

Tourism reveals the treasures of the host society to tourists from the guest society. Tourism is an integrated experimental system of cross-cultural exchange between the guest society and the host society. The decisive element to promote tourism is how the host society designs their treasures which the tourist gaze ${ }^{1}$ directs upon.

The Chubu district which is located in the center of Japan and surrounds Nagoya, Aichi has conserved and cultivated its treasures notably Karakuri Ningyo dolls stored at a few local museums and the mechanical exhibits displayed at Toyota Commemorative Museum of Industry and Technology (Toyota Commemorative Museum) on the basis of the political, economical, and spiritual uniqueness of its indigenous culture.

The Chubu district is one of the world's powerful manufacturing regions. Although the region receives large numbers of visitors for business, cultural, and nature tourism, it has not been generally recognized as an attractive destination for industrial tourism.

aOhkagakuen University, Japan

bMeijyo University, Japan

\section{Correspondent Author:}

Masami Morita, 1-505 Uedahigashi Tenpaku-ku Nagoya, Japan, Postcode: 468-0006

E-mail: judyedel1010@gmail.com 
The aim of this paper is to explore the significance of Karakuri Ningyo dolls and Toyota Commemorative Museum as resources of industrial tourism. This paper also will demonstrate the historical uniqueness of technology of Japan.

There are several places where the public can see Karakuri Ningyo dolls in the Chubu district. Karakuri Ningyo dolls are traditionally "wooden automata” exemplifying creative technology unique to Japan. Yet Karakuri Ningyo dolls have not been properly appreciated as a significant resource of industrial tourism. As the Chubu district has been evaluated as having a great ability to prepare a good foundation for industrialization, Karakuri Ningyo dolls are expected to be approved as industrial heritage.

Toyota Commemorative Museum is another important resource of industrial tourism in the Chubu district. It exhibits not only the path of Japan's industrial modernization with textile machinery and automobiles but also the Chubu district's ability to produce unique technology such as the Garabo Spinning Machine ${ }^{2}$. Toyota Commemorative Museum provides tourists with an opportunity to consider the creative industrial power connecting local industrial elements in Chubu district: cotton cultivation and manufacture, tree planting and the assembly by skilled woodworking craftsmen.

\section{CHUBU AS A TREASURE LAND OF KARAKURI NINGYO DOLLS}

\section{Definition of Karakuri Ningyo Dolls}

Karakuri Ningyo dolls are mechanical dolls designed to move by using the snap back power of springs or spirals made of whalebone and transmission devices of wooden gears or pulleys. Karakuri Ningyo dolls are "wooden automata" exemplifying ingenuity and skills unique to Japan. Karakuri Ningyo dolls had been popularized among the common people in the late seventeenth century of the Edo period (1603-1868).

Karakuri Ningyo dolls developed during the Edo period can be divided into Salon Karakuri and Dashi Karakuri in terms of the purpose of use. Salon Karakuri are typical examples of "wooden automata" represented by Teacup-carrying, calligrapher, and archer boy ningyo. They gave great pleasure to family members and visitors in not only the Imperial Court but also important merchants and rich farmers. Until the end of the Edo period, a large number of Salon Karakuri must had been made, but now a few only have been conserved as cultural properties in several local museums. Fortunately, we can see Salon Karakuri reconstructed by an excellent Karakuri Ningyo dolls engineer Tamaya, Shobei IX (1954- ) who lives in the Chubu district.

Dashi Karakuri means Karakuri Ningyo dolls set atop Dashi floats in festivals. Basically, they are manipulated by people hidden in Dashi floats pulling strings and pushing control rods. In terms of power source, Dashi Karakuri seems to be different from Salon Karakuri as "wooden automata", but around $20 \%$ of current Dashi Karakuri have similar kinds of escapement control apparatuses as Salon Karakuri $^{3}$.

Japan's oldest and symbolic festival with Dashi floats is Gion festival in Kyoto from the early the Muromachi period (1336-1573). However, the origin of Dashi Karakuri is found in Owari-Nagoya ${ }^{4}$ in the early Edo period. Since then, throughout the Edo period, for two centuries, Dashi Karakuri spread from Owari-Nagoya throughout Japan. Today, 300 years after its first appearance, there are about 200 of Dashi Karakuri currently available to see in Japan. Their geographical distribution is concentrated in the Chubu district especially Aichi and Gifu Prefectures. Around two thirds of the Dashi Karakuri in Japan are exhibited in their local festivals. Hence, the Chubu district is a Treasure Land of Karakuri Ningyo dolls and has cultivated the sense of Karakuri culture. 


\section{Birth of Karakuri Ningyo Dolls}

It is said that Takeda Karakuri or Karakuri by the Takeda family in Osaka provided the basic ideas and skills for the development of Dashi Karakuri. The technological base of Takeda Karakuri came from the Western mechanical clock which Francis Xavier, a Spanish Society of Jesus saint and missionary, brought into Japan in 1551. The Western mechanical clock was constructed with the mechanism of automaton such as escapement control apparatuses, spirals, gears, and cams.

On the basis of the technology of the Western mechanical clock, Tsuda, Sukezaemon developed Japan's unique mechanical clock Wadokei, the Japanese clock, for the Japanese uneven time system (Wadokei) in 1598. Tsuda was born in Kyoto and moved east to the feudal domain Owari to work as a clockmaker and soon reached the status of the head of smiths there. While the Tsuda family succeeded in making Wadokei for generations, Owari became another Wadokei producing district in line with Edo (today's Tokyo) and Osaka, and prospered in the industry until $1873^{5}$. Takeda, Omi was one of the many clockmakers who appeared following Tsuda, Sukezaemon. He applied the unique technology of Wadokei to create Karakuri Ningyo dolls. Without the contribution of Western mechanical clock's technology, Karakuri Ningyo dolls were not able to be created. Thus, the innovative ideas of Takeda Karakuri were supported by new technology which had incorporated Western technology into Japan's unique technology.

Takeda Karakuri, entertainments in theater, began in Osaka in 1662. The great success of Takeda Karakuri had business rivals and Karakuri performances became increasingly sophisticated. The Takeda family had successfully carried on the traditional business not only in Osaka but also in Kyoto, Edo, and Owari for around 100 years.

Takeda Karakuri were assimilated into the Joruri ${ }^{6}$
Puppet Theater in Osaka and into the Kabuki in Edo. In Owari, the tradition of Takeda Karakuri remained as Dashi Karakuri.

\section{The Spread of Dashi Karakuri in the Owari Domain}

The Edo period's place-names are different from the current ones. The territory of Owari included part of Aichi Prefecture and the southern part of Gifu Prefecture. The name Owari-Nagoya means the main parts of the current Nagoya city which is the central city of the Chubu district.

The popularization of Dashi Karakuri in Owari had its origin in the appearance of those in the Toshogu shrine festival which began in 1618. At the starting of the festival, there were Dashi floats with spiritual dolls, but until the early eighteenth century, all nine Dashi floats had been gradually transferred into Dashi Karakuri floats with Karakuri Ningyo dolls set atop. The festival was the biggest one in this area until the Second World War.

In the beginning of the Edo period (the early seventeenth century), the founder of Tokugawa Shogunate, Tokugawa, Ieyasu (1542-1616), requested construction of Nagoya Castle and the formation of the castle town of Owari-Nagoya as a politically strategic place against Osaka due to the establishment of central authority of the Edo government. Owari had been governed by the top of feudal lords directly descended from Tokugawa, Ieyasu. With the construction of Nagoya Castle in 1610, there was a flow of people and goods which gave energy to the emerging city and every class of people of samurai, Buddhist priests, and Shinto priests, craftsmen, and merchants had settled in the town.

Under the short reign of lord, Tokugawa, Muneharu, from 1730 to 1739, the festival parades of brilliant Dashi Karakuri spread throughout Owari. The laissez-faire governmental policy of Muneharu was against the control strategy of the third Tokugawa Shogunate, Tokugawa, Yoshimune, who encouraged 
every class of people to live simply and economically. The economic power which had supported the gorgeous events was brought by the rich granary of the Nobi Plain in Owari and the expensive Japanese cypresses of the Kiso forest within the domain.

In the early days of Dashi Karakuri, Takeda, Omi and other Karakuri artisans, or Karakuri Ningyo-shi, made business trips from Owari to Osaka and Edo to construct and mend the dolls. The first generation Tamaya, Shobei moved on to Owari from Edo in 1734. At about the same time, native Karakuri artisans appeared in Owari. They were called the name of Biyoudokushi and they engaged in the business related to the construction of Dashi Karakuri for festivals and Salon Karakuri for rich merchants in Owari until the end of the Edo period.

\section{Chubu as the Representative Area of Karakuri Culture}

The Karakuri entertainment business which was so successful in the eighteenth century disappeared in the modernized society of the Meiji period (1868-1912). Most Dashi Karakuri with a few exceptions were burned down during the Second World War of 1939-1945. Nevertheless, Dashi Karakuri have been carried in festivals in the Chubu district and elsewhere in Japan for over 300 years.

The family of Tamaya, Shobei, one of the famous Biyoudokushi, has inherited not only the technology of Karakuri Ningyo dolls but also the Karakuri culture of innovation from the first generation into the present ninth generation. They have created the computer controlled versions of Karakuri Ningyo dolls as well as repaired and reconstructed old ones.

Karakuri Ningyo dolls are an exemplification of cultural fruits born of Japan's creative mechanical technology incorporating Western clock technology with Japan's unique technology. Karakuri Ningyo dolls are becoming more well-known as cultural property. They should also be properly evaluated as resources of industrial tourism.

\section{TOYOTA COMMEMORATIVE MUSEUM}

\section{Toyota Commemorative Museum Introduction}

Toyota Commemorative Museum was established in 1994 at the location of the pilot factories built in 1911 by Toyoda, Sakichi (1867-1930) for research and development of automatic looms. Sakichi is the father of Toyoda, Kiichiro (1894-1952) founded Toyota Motor Corporation in 1937 and the Toyota Group. The buildings, made of red-bricks, are appreciated as an industrial heritage and are reused as space for displays. "The museum's mission was (sic) to systematically introduce the history of Japanese manufacturing technology to those who will be responsible for its future development"

The museum is located near Nagoya Station in Nagoya city, Aichi Prefecture. The museum covers an area of $41,600 \mathrm{~m}^{2}$ and within the site, there is an exhibition floor area of $14,300 \mathrm{~m}^{2}$ including the library, auditorium, museum shop, and restaurant. The exhibition area is divided into Textile Machinery Pavilion and Automobile Pavilion. The Textile Machinery Pavilion has an area of 3,468 $\mathrm{m}^{2}$ and exhibits 95 different spinning and weaving machines. The Automobile Pavilion consists of four zones of automobile mechanisms, component parts, automotive technology, and manufacturing technology, and exhibits some 4,000 items in $7,900 \mathrm{~m}^{2}$. Visitors enjoy dynamic displays of original equipment, demonstrations by operators, and instructive videos.

The museum demonstrates the developing, improving, and creative processes of manufacturing looms invented by Toyoda, Sakichi and Kiichiro, and how the technological achievement of making looms was applied to automobile production. The museum also shows the path of Japan's technological progress from textile machinery to the current automobile engineering. The museum is a treasure house of Japan's industrial modernization and development of automatic mechanism. 


\section{Toyoda, Sakichi and His Power Looms}

Toyoda, Sakichi was born in 1867 in today's Shizuoka Prefecture. His first invention was the Toyoda Wooden Hand Loom assembled in 1890, and "Loom" was patented in 1891. The loom was an improved version of the Hand Loom with Battan (fly shuttle), Japan's tall loom by setting up the Western fly shuttle. Sakichi improved several looms and invented the Toyoda Power Loom, a narrow width loom $^{8}$, made of both wood and iron. Under the industry promotional policy of the Meiji government, spinning mills introduced Western spinning machinery and power looms in the late nineteenth century. However, those mills did not succeed because most cotton suppliers were farmers' cotton factories and small-sized local textile businesses using hand looms, especially in Aichi Prefecture where cotton cultivation and manufacturing prospered since the Edo period.

Sakichi's power looms improved productivity and the quality of the products. The power loom was not just an imitation of the Western technology but an improvement combining Japan's traditional technology and Western technology such as the Garabo Spinning Machine.

While Sakichi started his career as an entrepreneur of the retail outlet, Toyoda Shoten, established in 1895, he devoted himself to developing power looms. In 1909, he invented the Toyoda Power Loom Type L with wide width. This advanced Type L technology achieved a comparable level of the technology with imported spinning machinery such as made by Platt Brothers \& Co., Ltd. in the UK, which was the world's prominent textile machinery manufacturer at the time.

\section{Toyoda, Kiichiro and His Automatic Looms}

Toyoda, Kiichiro carried out research and development with Sakichi in order to perfect the Automatic Loom with Non-Stop Shuttle Change
Motion, Type G, which was realized in 1924. Kiichiro graduated from the Faculty of Engineering of Tokyo Imperial University (today's Tokyo University) and trained in Platt during his grand tour to Western countries of 1921-1922. As a result of his learning and experiences, Kiichiro succeeded in creating automatic looms of world's leading-edge technology.

The path from Toyoda's hand looms to power looms, and automatic looms illustrates the ingenuity of Toyoda, Kiichiro in a process incorporating Japan's technology with Western technology. Type G embodied the creativity involved in the development of Japan's technology exceeding even Western spinning machinery.

In 1926, Toyoda Automatic Loom Works, Ltd. (TALW) was founded for mass production of Type G. The automatic looms were sold to domestic weaving companies and exported overseas. TALW continued to develop their business, and they signed a patent transfer agreement with Platt in 1929. Before arriving at Platt for signing the contract, Kiichiro travelled in Europe and the US again.

\section{FROM TEXTILE TO AUTOMOBILES}

According to 75 Years of TOYOTA 9 , "When Kiichiro established TALW; he already anticipated entering the automotive industry and had created plans for machine tool (sic.) and casting facilities”. The numerous introduced machines ${ }^{10}$ were later adopted for automobile production. The plant also had an assembly line using a chin conveyor for production of automatic looms.

On his two overseas trips, Kiichiro observed industrial structure undergoing many changes and focused on observation of the automotive industry and machine tools. In 1930, when Kiichiro came back from the US, the downturn in the cotton industry became more serious in the Great Depression of 1929. 
Under these economic conditions, Kiichiro started his research relating to automobiles.

In 1933, Kiichiro decided to enter the automobile business and the Automotive Production Division was established in TALW. The preparation project following this decision progressed steadily from construction of a plant for prototype production and a steelworks in 1934, through completion of the first Type A engine in 1934, completion of the first Type A1 passenger car prototype, the Model G1 prototype truck in 1935 and to the commencement of mass production of Model AA passenger cars in 1936.

The Automotive Production Division was spun off from TALW and Toyota Motor Co., Ltd. was established in 1937. Koromo Plant was completed and flow and "Just in Time" production was started in 1938. As well as the technology of textile machinery and mass production from TALW, Toyota Motor Co., Ltd. inherited the spirit of the pursuit of research and creativity. This company culture of seeking to research and create greatly contributed to the evolution of Toyota Motor Co., Ltd. into today's Toyota Group and elevating it to become one of the world's leading company groups.

The exhibits of Toyota Commemorative Museum not only demonstrate textile machinery and the development of automotive technology from Toyota's core industries. They embody the culture of Toyota which helped promote the modernization of Japan. The museum is a treasure house of Japan's industrial modernization and the development of automatic mechanisms.

\section{CONCLUSIONS}

The following three points were explored.

(1) Karakuri Ningyo dolls and Toyoda looms shared similar course of creative technological development.

Karakuri Ningyo dolls are "wooden automata" exemplifying ingenuity and skills unique to Japan. Without the contribution of Western mechanical clock's technology, it would not have been possible to create Karakuri Ningyo dolls. Karakuri Ningyo dolls are an exemplification of cultural fruits born of Japan's creative mechanical technology incorporating Western clock technology with Japan's unique technology.

The path from Toyoda's hand looms to power looms and automatic looms illustrates the ingenuity of Toyoda, Kiichiro in a process incorporating Japan's technology with Western technology. Type G embodied the creativity involved in the development of Japan's technology exceeding even Western spinning machinery at that time;

(2) The Chubu district is one of the representative industrial tourism destinations which the tourist gaze directs upon.

The Chubu district is a treasure land of Karakuri Ningyo dolls and has cultivated the sense of Karakuri culture. Around two thirds of Dashi Karakuri in Japan are currently available to see in the local festivals. The family of Tamaya, Shobei has inherited not only the technology of Karakuri Ningyo dolls but also the Karakuri culture of innovation from the first generation to the present ninth generation in this district.

It can be said that Karakuri Ningyo dolls' technology of escapement control apparatuses was the early pioneer of Toyoda Kiichiro's Type G automatic loom with a nonstop shuttle-change motion as Japan's first power loom, Toyota Production System with robot control and automation with a human element and farther humanoid robot development;

(3) Toyota Commemorative Museum provides tourists with an opportunity to consider the creative industrial power connecting local industrial elements in the Chubu district.

The exhibits of the museum not only demonstrate the technology of textile machinery and the development of automotive technology of Toyota, but 
also embody the Karakuri culture and the Toyota company culture of seeking to research and create which helped promote the modernization of Japan. The museum is a treasure house of Japan's industrial modernization and the development of automatic mechanisms.

Making efficient use of Karakuri Ningyo dolls and Toyota Commemorative Museum of Industry and Technology as resources of industrial tourism is needed all the more to vitalize the Chubu district and demonstrate the historical uniqueness of technology of Japan.

\section{APPENDIX}

\section{Salon Karakuri}
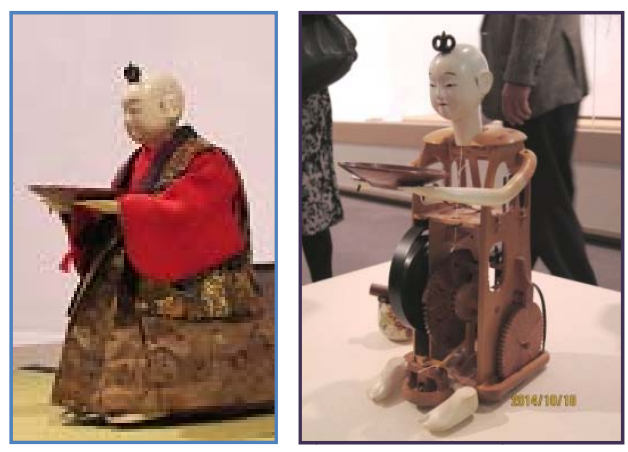

(A tea-cup carrying Karakuri Ningyo doll photographed by Shinji Morita, October 18, 2014)

Salon Karakuri are representatives of "wooden automata”. The naked teacup carrying Karakuri Ningyo doll shows his moving mechanism well.

A Karakuri Ningyo doll named Calligrapher or Mojikaki Ningyo wrote Japanese characters "bamboo" with a holding brush between his teeth and "pine" with a handing brush simultaneously.

Another type of Karakuri Ningyo doll named Archer boy or Yumihikidoji hits the target with an arrow correctly. The distance from him to the target is around $80 \mathrm{~cm}$.

\section{Karakuri Zui}

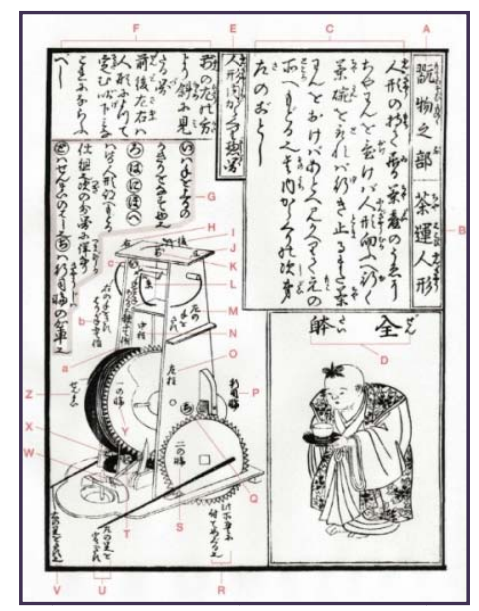

[Explanation of tea-cup carrying Karakuri Ningyo doll from Murakami (2012). Japanese Automata, p. 102]

These secret technologies and skills were opened to the public by the book named Karakuri Zui written by Hosokawa, Hanzo and published in 1796. It was a manual of automatic mechanical devices. Japanese Automata published in 2012 is a complete translation of Karakuri Zui in English by Murakami, Kazuo.

3. Dashi Karakuri

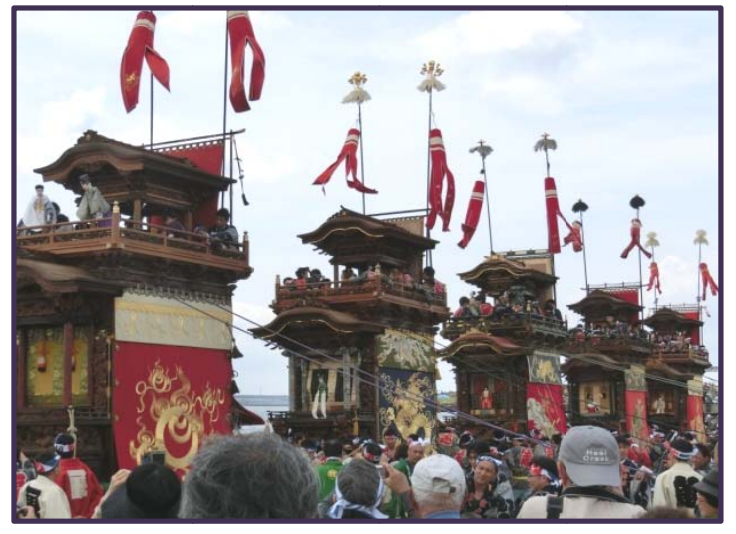

(Dashi floats with Karakuri Ningyo dolls in a festival called Shiohimaturi in the Chita Peninsula in Aichi Prefecture photographed by Masami Morita, May 4, 2015)

4. Distribution of Dashi Karakuri 


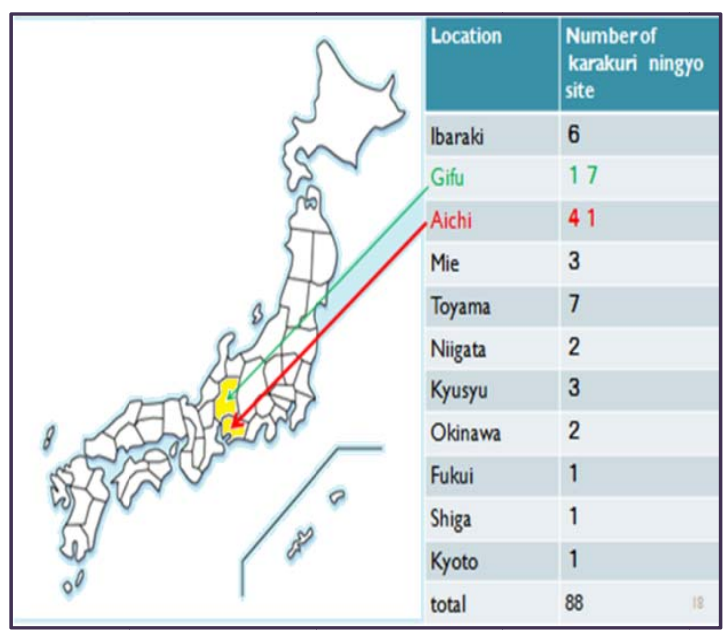

[From: Senda (2012). Karakuri Ningyo, p. 36]

5. The Image of the Path of Technological Development in Japan

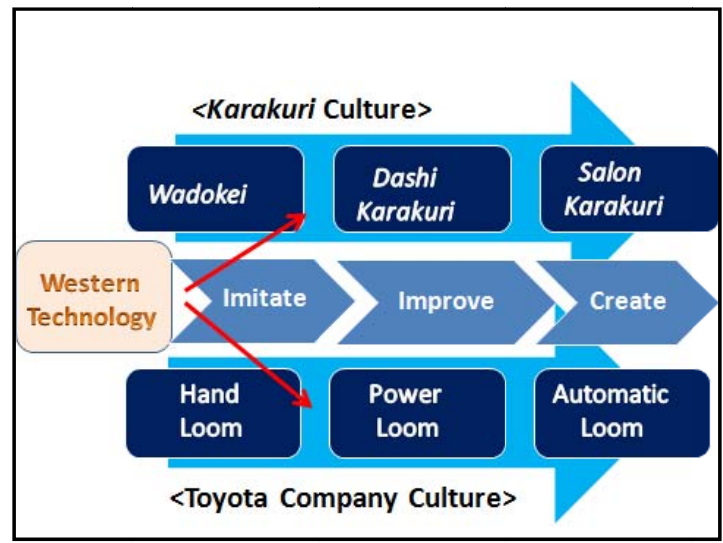

(made by Masami Morita)

6. The Exhibits of Toyota Commemorative Museum of Industry and Technology

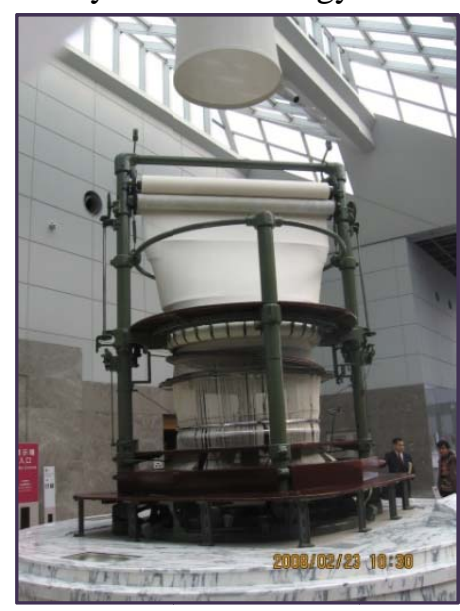

(The Circular Loom photographed by Shinji Morita, February 23, 2008)
The Circular Loom symbolizes the two key spirits of the museum "Making Things" and "Research and Creativity" to which Toyota Commemorative Museum of Industry and Technology is dedicated.

In the next photo, we can see a Karakuri Ningyo doll placed at the corner of the exhibits of control apparatus system in the automobile pavilion.

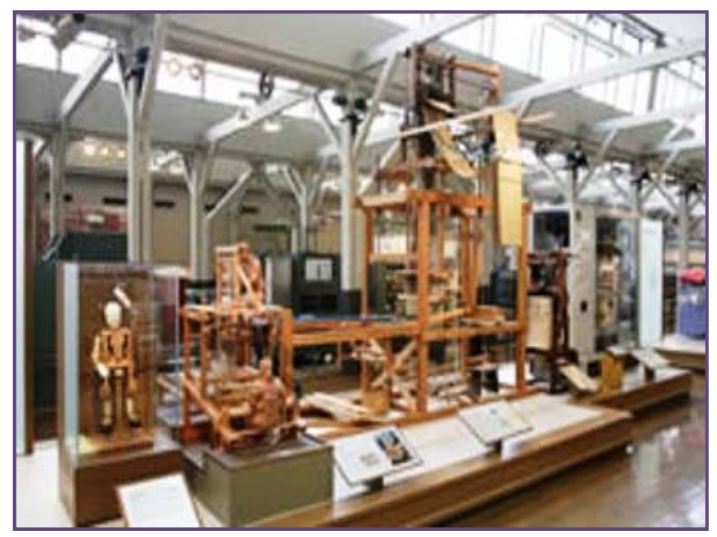

(From: Toyota Commemorative Museum HP)

7. A Karakuri Ningyo Doll Teaches "Monozukuri" to Employees From Different Countries

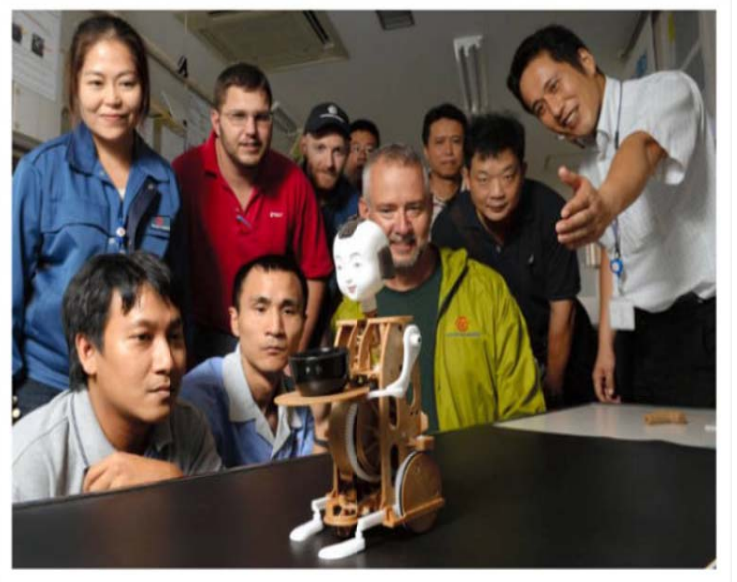

(From: Chunichi Newspaper, July 23, 2014)

They were learning at training center of Toyoda Gosei which manufactures automotive components; 43\% owned by Toyota Motor is one of the 17 members of Toyota Groupe. The article said that the technical history of Toyota began from Karakuri and the founder of Toyota Group, Toyoda, Sakichi's Loom owed a lot to the craftsmen's skills and minds of the Edo period. 


\section{Acknowledgements}

The authors would like to thank Leslie Chivers, Associate Professor at Ohkagakuen University and Tetsu Suzuki, Part-time Lecturer at Ohkagakuen University and National Licensed Tour Guide for her/his enormous support in this research. All remaining errors are the authors' own.

\section{Notes}

1. John Urry used the concept of the gaze drawing from Michel Foucault's gaze to explain tourist's systematic ways of seeing. Urry, John. 1990. The Tourist Gaze: Leisure and Travel in Contemporary Societies. London: Sage.

2. The garabo spinning machine was invented in 1873 by Tokimune Gaun, a technologist from Shinano (now Nagano Prefecture). This spinning machine had a unique design, allowing the formation of yarn directly from a lump of fiber. It is referred to as a gara-spinner because when it was in operation, it made a noise that sounded like "garagara" (p. 22). The Toyota Commemorative Museum of Industry and Technology. 1995. Total Guide to the Toyota Commemorative Museum of Industry and Technology. Nagoya, Japan: S.T.C.Inc.

3. The authors counted the number of such Dashi Karakuri as some 200 from the appendix of Takanashi, Seima. 2004. Karakuri Ningyo no Bunkashi (Records of Karakuri Ningyo Dolls Culture). Tokyo: Gakugei Shorin.

4. Owari-Nagoya is the old province name of the main city, Nagoya in Owari Province, west of current Aichi Prefecuture.

5. The Japanese government adopted the Western style even time keeping practice in 1873.

6. Joruri's dialogues and narratives are recited to a shamisen accompaniment.

7. Website of Toyota Commemorative Museum of Industry and Technology. Museum Objective. Accessed May 20, 2015 (http://www.tcmit.org/english/online/index.htm).

8. The loom had a wooden frame combined with iron gears and shafts in the power transmission mechanism.
9. The history of TOYOTA Groups in 75 years. Accessed May 20, 2015 (http://www.toyota-global.com).

10. The machines were high-precision foreign-manufactured machine tools, special-order frame hole three-axis boring machines, planer four-axis drilling machines, frame cutting machines, electric furnaces, and foreign-manufactured molding machines for casting.

\section{References}

Abo, K. 2008. Chubu no Sangyo: Kozohenka to Kigyokatachi (Industry in the Chubu District: Structural Change and Entrepreneurs). Osaka, Japan: Seibundo.

Murakami, K. 2012. Japanese Automata: Karakuri Zui: An Eighteenth Century Japanese Manual of Automatic Mechanical Devices. Shiga, Japan: Taiga.

Nakaoka, T., T. Ishii, and H. Uchida. 1986. Kindainihon no Gijyutu to Gijyutuseisaku (Technological Development and Technology Policy in Modern Japan). Tokyo: United Nations University.

Senda, Y. 1992. Karakuri Ningyo no Hoko (The Treasure House of Karakuri Ningyo Dolls). Nagoya, Japan: Chunichi.

—. 2012. Karakuri Ningyo Dolls: Japanese Automata. Translated by T. Slemmons. Australia: StageWorks.

Tatsukawa, S. 1980. Karakuri (Karakuri). Tokyo: Hosei University Press.

Wada, K. and T. Yui. 2001. Toyoda Kiichiro Den (Biography of Toyoda Kiichiro). Toyota, Japan: Toyota Motor Corporation.

\section{Bios}

Masami Morita, MA in economics, professor, Faculty of Liberal Arts, Ohkagakuen University, Japan; research fields: industrial tourism, regional economics, and transport economics.

Shinji Morita, MA in business administration, professor, Faculty of Business Management, Meijyo University, Japan; research fields: business management, business history, and manufacturing management. 